\title{
Theologie Und AufKLÄrung
}

\author{
Untersuchungen zum Problem ihrer Vermittlung \\ in Texten des jungen Hegel
}

INAUGURAL-DISSERTATION

zur ErLangung des Doktorgrades

DER PHILOSOPHISCHEN FAKULTÄT

DER JoHanN Wolfgang GoEThe-UNIVERSITÄT

in Frankfurt am MaIN

\author{
VORGELEGT \\ VoN \\ HANS-JOACHIM KRÜGER \\ AUS BERLIN \\ 1964
}


1. Gutachter: Prof. Dr. Horkheimer

2. Gutachter: Prof. Dr. Adorno

Tag der mündlichen Prüfung : 8. Juli 1964

ISBN 978-3-476-99552-0

ISBN 978-3-476-99551-3 (eBook)

DOI 10.1007/978-3-476-99551-3

Diese Arbeit erscheint gleichzeitig als Buch unter dem Titel "Theologie und Aufklärung. Untersuchungen zu ihrer Vermittlung beim jungen Hegel« in der J. B. Metzlerschen Verlagsbuchhandlung Stuttgart 
VORWORT

Die Arbeit ist zu einem inneren Dialog mit den analysierten, zumeist älteren Texten geworden. Der Frage nach der Aktualität der Philosophie Hegels sollte damit nicht ausgewichen werden. Ihre Beantwortung wird aber davon abhängig sein, sich der Motive zu vergewissern, die für die Denkbewegungen dieser Philosophie bestimmend waren.

Der Studienstiftung ist für die Förderung der Arbeit zu danken. Für das Interesse an den Aspekten und für kritischen Rat danke ich den Herren Professoren Max Horkheimer, Theodor W. Adorno und Karl Heinz Haag.

Frankfurt/Main, November 1965 H. -J. K. 
EINLETTUNG . . . . . . . . . . . . . . . . . 1

I. Restitution theologischer MEtaphysix IN DER AUfKLäRUNG 6

Die articula fidei, das nominalistische Tabu (Ockham) . . . 6

Theologie der Entfremdung (Luther) . . . . . . . . . 9

Absolutismus als theologischer Einwand gegen Emanzipation 9

- Die private und die öffentliche Freiheit eines Christenmenschen 11 - Antinomien der Unabhängigkeit 14 - Natur als Rechtfertigung von Herrschaft 16 - Konturen des Unerkennbaren 17

Tautologische Einheit von göttlicher und menschlicher Vernunft (Herbert von Cherbury) . . . . . . . . . . . . . .

Hierarchie der Sensorien 19 - Aquivokationen des Naturbegriffs 21 - Invarianz als Wesensbestimmung 21 - Naturwissenschaftliches und religionsphilosophisches Subjekt 23

Positives als göttliches Gesetz (Hobbes) . . . . . . . .

Vorbild Technik 24 - Gesselschaftliche Implikationen des Naturbegriffs 26 - Theologie als Beleg 27 - Arbeitsteilung der Herrschaftsressorts 28 - Ausgeborgter Nimbus der absoluten Gesetze 30 - Blindheit als Forderung der Vernunft 32

Omnipotente Natur (Holbach) . . . . . . . . . .

Religion ohne Geltung - Genesis als Prinzip 33 - Gesellschaftskritik und Naturpositivismus 35 - Konstruktive Negativität 36 - Theodizee der Natur 37 
Dialektik im Konjunktiv (Hume) . . . . . . . . . .

Kritik der deistischen Analogien 38 - Atheistischer Supranaturalismus 39 - Geschichtliche Strukturierung von Natur und Gesellschaft 40 - Aufklärung und das Noch-nicht-Bekannte 41

II. Aufklärung und Geschichte - Verwicklungen als LeitFÄDEN

Absolutismuskritik des Eigentümersubjekts (,Volksreligion und Christentum $^{6}$ ) . . . . . . . . . . . . . . . . .

Fragment und System 44 - Biedermeierrevolte - aufklärerischer und religiöser Absolutismus 45 - Das Programm: Subjektivierung objektiver Religion 48 - Politisch-religiöse Aneignung 51 - Dialektik der Projektion 52

Herrschaftskritik des geschichtlichen Subjekts . . . . . .

Aus zwei mach eins: Gibbons sekundäre und primäre Ursachen 54 - Dogmen ohne Begrifflichkeitsalibi 55 - Gegenbilder: blühender und welkender Genius 56 - Programmkorrekturen - Religions- als Herrschaftskritik 58

Ambivalente Positivität (,Die Positivität der christlichen Religion') . . . . . . . . . . . . . . . . . . .

Problematischer Abstand: christliche Gesellschaftskritik 62 Problematische Einheit: christliche Staatsreligion 64 - Ecclesia invisibilis - die philosophische Sekte 66

Motive des Religions- und Moralitätsinteresses . . . . . .

Der naturgeschichtliche Rest 67 - Lessings Rauchfang: das moralische opus supererogatum 69 - Politischer Legalismus 70 - Auswege: Arbeitsteilung 74 / Revolution 76 - Aporien 78

Das unsichtbare Subjekt (,Der Geist des Christentums und sein Schicksal') . . . . . . . . . . . . . . . . .

Zur identitätsphilosophischen Wende 80 - Schicksale der Schicksalsschrift 81 - Kritik der kritischen Subjektivität 86

Rückversicherte Vermittlungen . . . . . . . . . .

Libertinismus auf Abruf 88 - Spinozas Vorbehalt 89 - Politische Schockreaktion: Schillers ästhetischer Staat 90 - Kant: Schutz vor windigen Synthesen 95 - Herr Bürger - der fremde und der eigene Herr 98 - Unentbehrliches Chaos 99 
Versöhnung ohne Erlösung . . . . . . . . . . . . 101

Vorbegriffliche Identität 101 - Mystisch umgangener Mythos 103 - Begrifflicher und ökonomischer Tausch 104 - Der romantische Wink: Analogie und Vermittlung 107 - Immanente Versöhnung 111 - Der altgute Freund 124 - Kleine Verlustliste 128

III. Philosophische Liberditismusrezeption . . . . . . . . 132

Exkurs 1: Gesellschaftlich notwendiges Azivilisatorisches (Mandeville) . . . . . . . . . . . . . . . . . 132

Mediokre Tugend 132 - Das Ubertier Mensch 133 - Manieristischer Himmel 135 - Immoralität als faux pas 137 - Alarmierende Harmonien 137 - Notwendige Abstände 140 - Für Arbeit verkaufen die Götter fast alles 142

Exkurs 2: Gesellschaftlich eingeholter Naturgegensatz (Smith)

Gar nicht so schlechte Entfremdung, Teilen und Tauschen 143 - Metamorphose der Naturbestie 145 - Die Welt, ein Sozialmärchen 146

Antinomien der Realphilosophie (»Jenenser Realphilosophie $I_{\aleph)}$. . . . . . . . . . . . . . . . . . . . . 151

Anteil der Arbeit an der Menschwerdung des Menschen 151 Abweichungen vom Vorbild 155 - Vermittlung von oben 157 Utopische Wolkenbilder 161

ANMERKUNGeN . . . . . . . . . . . . . . . . . 163

LITERATURVERZEICHNIS . . . . . . . . . . . . 172 
Theologie

UND

AUfKLÄRUnG 